\title{
Improving Overall Equipment Effectiveness (OEE) of process plant equipments through e-Diagnostics.
}

\author{
Trinath Sahoo \\ Indian Oil Corporation Ltd, India
}

\author{
Aditya Parida \\ Luleå University of Technology \\ Sweden, aditiya.parida@ltu.se
}

\begin{abstract}
The concept of e-maintenance is wide spread in industry which integrates ICT (information and communication technology) within the maintenance strategy to face the new challenges of supporting e-manufacturing. The maintenance support which includes in the resources, services and management, are necessary to enable proactive decision making which includes etechnologies( ICT, web based ,wireless etc.) and e-maintenance activities; such as e-monitoring, e-diagnostics and e-prognostics. The monitoring of machines and processes for predictive maintenance and control is critical for sustainable and competitive industry. E-diagnostics is a key component for implementing emaintenance for the cutting edge of high capital intensive plant.
\end{abstract}

Keywords: e-diganostic, OEE, e-Maintenance, predictive maintenance, Maintenance support

\section{INTRODUCTION}

The manufacturing and process industry use Overall Equipment Effectiveness (OEE) as an important Key Performance Indicator (KPI) to monitor and control their performance effectiveness. This KPI is applied as an overall indicator in the Total Productive Maintenance (TPM) concept (Nakajima, 1988). OEE is an aggregated productivity measure that takes into consideration the six big losses which affects the productivity of plant and equipments in an operational system. Equipment failure, setup, and adjustments are related to down time and expressed in terms of availability. Idling and minor stoppages together with reduced speed are related to speed looses and expressed in terms of performance rate. Finally, process failures or defects and reduced yield related to quality defects are expressed in terms of quality rate. OEE itself simply multiplies the equipment's availability, performance rate, and quality rate. Normally, OEE figures can be found between 30 - 95 \% (Ljungberg, 1998). Various aspects of OEE can be found in the literature. It is the availability metric that is targeted in these discussions. Some authors claim that the availability metric is influenced by factors beyond the equipment itself such as operators, facilities, input material availability, scheduling requirements, etc; i.e. the OEE metric is reflecting the integrated equipment system and not the stand-alone equipment themselves (De Ron and Rooda, 2005, De Ron and Rooda, 2006). Others are arguing that the OEE metric is not taking into consideration all factors that reduces the availability such as planned downtime and lack of material and labour (Ljungberg, 1998, Sheu, 2006).
To develop control indicator or to launch maintenance improvement program, we need to streamline the information logistic: "right information in right formats and form to right person in right time" (Parida and Kumar, 2004). Condition monitoring uses various intelligent health monitoring techniques to monitor and control the health status of plant and machineries by analyzing the data after it has been collected. The application of information and communication technologies (ICT) facilitates the on-line and off-line condition monitoring and measurement of degradation of plant and machineries. (Parida and Kumar, 2004)

Plant and equipment health management system (PHMS) is an approach for corrective, preventive and predictive maintenance besides other support activities. With a need to achieve zero down time, zero defect, instantaneous response and decision-making and world-class OEE performance; prognostics and diagnostics are used through embedded sensors and device to business tool (D2B). All these needs have lead to e-health card for equipment's degradation assessment, which forms part of e-maintenance. PHMS thus, could consist of condition monitoring (CM) based diagnostics and prognostics, and condition based operation and support, to improve the dependability and safety of the technical systems, besides decreasing life cycle cost of operation and support (Campbell and Jardine, 2001; Soderholm and Akersten, 2002). This system delivers data and information, which indicates the health condition of the system. The stakeholders of the system are the receivers of the data and information (Lyytinnen and Hirschheim, 1987; ISO/IEC 15288, 2002). The problem today in a health management system is the existing information islands, i.e. the different specialized systems, with in an organization speaking a different data and information language. (Parida and Kumar, 2004)

Some of the existing e-maintenance solution provide the server based software, equipment embedded internet interface devices (health management card). These e-maintenance solutions provide $24 \times 7$ (24 hours 7days a week) real-time monitoring, control and alerts, at the operating centre. This system converts data in to information, available to all concerned for decision-making and predicting the performance condition of the plant and machineries on a real time basis. This enables the system to match with the ebusiness and supply chain requirements. For example, once the supervisor knows the plant degradation condition, its related effects on material, and inventory, then the delivery status can be planned and coordinated with a greater speed to satisfy the customer (Parida and Kumar, 2004).

The business scenario is focusing more on e-business intelligence to perform transaction with customers needs for enhanced value and improvement in asset management. Such prognostic business requirement is compelling the organizations to minimize the 
production and service downtime by reducing the machine performance degradation. The above organizational requirements necessitate developing proactive maintenance strategies to provide optimized and continuous process performance with minimized system breakdowns and maintenance.

e-Maintenance provides the organization with intelligent tools to monitor products through web-enabled wireless communication system focusing on health degradation monitoring and prognostics, instead of fault detection and diagnostics. This system converts data in to information, available to all concerned for decision-making and predicting the performance condition of the plant and machineries on a real time basis. This enables the system to match with the e-business and supply chain requirements. For example, once the supervisor knows the plant degradation condition, its related effects on material, and inventory, then the delivery status can be planned and coordinated with a greater speed to satisfy the customer (Parida et al., 2004). e-Maintenance creates a virtual knowledge centre with users (e.g. technicians, experts and the manufacturers) specializing in operation and maintenance of process industry like; steel, mining and paper amongst others. e-Maintenance can provide solution in its entirety for the process industry with an objective to reduce the overall costs, bring in a change and savings in resources through overall equipment effectiveness (OEE) and return on maintenance investment (ROMI).

\section{CONCEPT OF e-MAINTENANCE}

Maintenance functions sustain and improve the system's availability, safety and product quality. Development of ICT has contributed to the emergence of e-Maintenance concept since early 2000, which has become a common term in the maintenance related literature today (Muller et al., 2008). e-Maintenance can be defined as a maintenance strategy where tasks are managed electronically using real time equipment data obtained through digital technologies (i.e. mobile devices, remote sensing, condition monitoring, knowledge engineering, telecommunications and internet technologies (Tsang, 2002). eMaintenance is also considered as a maintenance plan to meet the productivity through condition monitoring, proactive maintenance and remote maintenance through real time information for decision making. Koc and Lee (2001) referred e-Maintenance as predictive maintenance system which provides only monitoring and predictive prognostics functions. e-Maintenance thus can be termed as a maintenance support for the E-Operation through remote diagnostics and asset management, simulation for optimisation and decision making under an E-Business scenario for an organisation.

Modern production environment demands an elevated degree of plant and equipment reliability involved in manufacturing process. Technological advances have changed the way the plant and equipments are being maintained. This change is aimed at continuous monitoring of the condition of the asset so as to sense the malfunctioning of their operating condition. Its importance is dictated by the fact that any change in the asset condition have a direct impact on critical business aspects such as production ,resource planning etc. in case there is failure is developing it is important to plan maintenance execution and related resources ahead of time. An essential requirement in this regard is the continuous availability of the condition monitoring information and its analysis in order to predict failure condition as soon as the asset starts deviating from its standard operational behaviour.

e-diagnostics is a technology for accessing production equipment at manufacturer production base via network to carryout remote diagnostics, thus achieving reduction in maintenance management cost as well as failure prediction and prevention. From the perspective of equipment vendors and asset owners the ultimate goal of e-diagnostics is the prediction of failure. If situation can be grasped before equipment abnormality occur, allowing for measures to be taken in advance, this would contribute significantly to improved OEE. There are two main type of equipment information that can be acquired via internet .Equipment operation log files, such as gas flow, pressure etc another is equipment failure diagnostic system that enables monitoring of machine health. This can be achieved if equipment experts at service centres can use the internet, a fast and inexpensive communication infrastructure to conduct diagnostics and analysis of onsite equipment.

The e-diagnostics is divided in to four levels. (Wohlwend, 2005)

Level 0: access and remote collaboration (remote connectivity to the tool and remote collaboration capabilities, field service access).

Level 1: collection and control (remote performance monitoring, data collection and storage)

Level 2: analysis (advanced reporting, advanced analysis with SPC capability)

Level 3: prediction (predictive maintenance, self diagnostics, automated maintenance)

\section{3. e-DIAGNOSTICS SUPPORT SYSTEM}

Data security is very important .All information is protected using advanced security functions including login authentication and authentic function at various stages. Only authorized person may be able to access the view based, relevant data to perform diagnosis. When executing remote diagnostics using e-diagnostic system, the following points must be taken in to consideration. The security of data must be assured due to concern regarding negative effects on production process and leak of confidential production data. Firewall friendly technology enables application in an environment protected by high level security. Various functions required for e-diagnostics can be achieved by preparing built in software. These functions include internet communication, real time data acquisition, and user authentication, mutual security between data bases, remote management and e-mail notification

An e-diagnostic support system installed by a device manufacturer regularly accumulates equipment information , such that both the device manufacturer and the device vendor can confirm the current operation status via web browser In the event that some type of abnormality occurs in the equipment, the production line equipment manager or the equipment vendor is automatically notified via e-mail. In addition to preventing the product failure before they occur, this enables equipment failure counter measures to be initiated from an early stage thus reducing no of failures and shortening MTTR. Development in sensor 
technology, signal processing, ICT and other technologies related to condition monitoring and diagnostics allow the maintenance area to improve the understanding of cause of failure, better monitoring to move from failure detection to degradation monitoring.

Depending on the details and condition of the failure, the operator can gain shared access to equipment screens, making it possible to confirm equipment status or acquire important information stored in the data collection controller from a remote location and to quickly determine the causes of failure. Further by statistically analyzing past equipment information and effectively using the result of those analyses, the device manufacture is able to reduce the cost of equipment maintenance.

Introduction and installation of e-diagnostics system offers significant merits for device manufacturer with multiple production bases. This is because parties conducting maintenance management and process management, for production facilities are able to carryout remote monitoring and diagnostics of equipment, either interactively or all at once with DCS and intranet. For asset management it means an integrated environment that not only monitors the condition of asset but also predicts failure condition as well as generates relevant maintenance recommendations and work request. Condition information is captured through an array of sensors.

\section{4. e-PROGNOSTICS}

The continuous prognostics (Lee et al., 2004) is aimed at detecting failure condition in development rather than failure reporting, whereby the aim is to reduce maintenance time and as a consequence increase operational time. This assessment generates recommendation for repairs or part replacement required to carryout maintenance. This framework not only provides for continuous availability of the asset but also ensures cost effectiveness by aiding in maintaining critical stock levels of essential spares, identification of maintenance resources and easily planning and scheduling of standby assets. These features ensure that the maintenance process is highly responsive and based on informed decisions rather than common judgments.

This framework can be applied to e-enabled manufacturing paradigm. For example in a crude pumping station is located away from major infrastructure and considerable length of pipeline that bring crude oil from sea coast to refinery. In this situation, assets are deployed over an area of various kilometres; however the demand of crude is continuous. Although the station may have some kind of early warning or process control and condition monitoring system such as SCADA (Supervisory control and Data Acquisition), maintenance labour at the water station as well as the pipeline is limited and spare inventory is generally not held at each station. Therefore it is imperative to continuously monitor asset operation in order to sense asset failure as soon as possible and preferably in their development stage. The SCADA system is used in the industry since 1960s. These systems are used to monitor the critical assets and provide early warning of potential disaster situation. In the cross country pipe lines the leakage is detected thru SCADA system and transfer the information back to the central site then alerts the home station that a leak has occurred, carrying out necessary analysis and control, such as determining if the leak is critical .
SCADA system also is used to detect the faults of remote unmanned electrical substations to avoid emergencies.

\section{RECIPROCATING COMPRESSOR DYNAMIC ANALYSIS, A CASE STUDY OF HYDRO CRACKING UNIT IN A PETROLEUM REFINERY}

Hydro cracking process is gaining more and more popularity for upgrading residues into higher value products in petroleum refinery. Residue up gradation into middle distillates and light distillates is currently being done in the Indian Refineries primarily by employing FCC process. Hydrocracking is an extremely versatile catalytic process in which feedstock ranging from Naphtha to Vacuum Residue can be processed in presence of Hydrogen and catalyst to produce almost any desired products lighter than the feed. Thus if the feed is Naphtha, it can be converted into LPG and if feed is Vacuum Gas Oil as in our Refinery, it can produce LPG, Naphtha, ATF, Diesel and FCCU feed in varying proportions as per design requirement. Compressor is the heart of the hydro processing plant of a Petroleum Refinery. Monitoring of this machine and failure prognosis plays vital role on plant availability. Reciprocating compressors are often some of the most critical and expensive systems at a petroleum refinery, and deserve special attention. Gas transmission pipelines, petrochemical plants, and many other industries all depend on this type of equipment also. Reciprocating compressors are typically used where high compression ratios (ratio of discharge to suction pressures) are required per stage without high flow rates, and the process fluid is relatively dry.

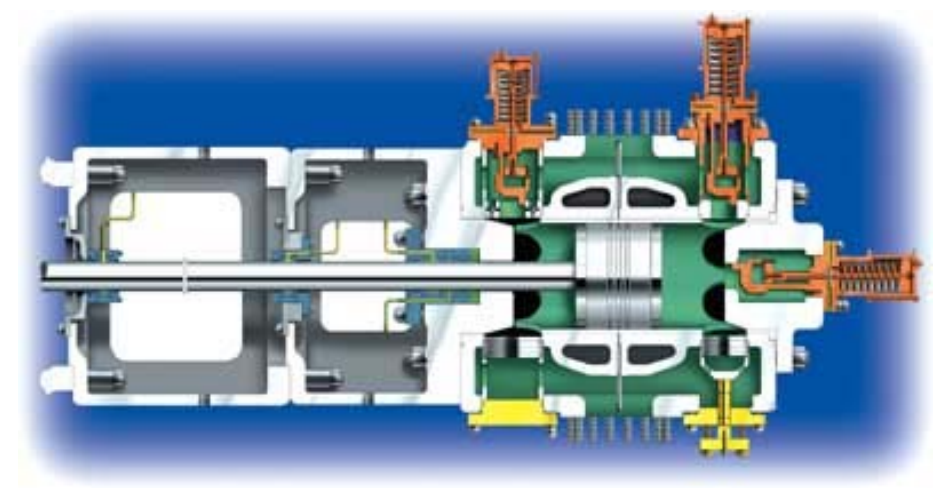

Figure 1. Reciprocating Compressor Cylinder Assembly

Process gas is drawn into the cylinder, squeezed, contained and then released by mechanical valves that typically operate automatically by differential pressures. Depending on system design, cylinders may have one or multiple suction and discharge valves. The distance piece (sometimes called the doghouse) is a structural member connecting the compressor frame to the cylinder. Intermixing of fluids between the cylinder and the distance piece must be avoided. Packing rings contain gas pressure within the cylinder, and they keep oil from entering the cylinder by wiping oil from the piston rod along its travel. The distance piece is typically vented according to the most hazardous material in the system, which is often the gas compressed in the 
cylinder. The packing rings are designed to contain the gas within the cylinder, but with the high pressure it is possible that some of the compressed gas will leak past the packing rings.

Compression occurs within the cylinder as a four-part cycle that occurs with each advance and retreat of the piston (two strokes per cycle). The four parts of the cycle are compression, discharge, expansion and intake. They are shown graphically with pressure vs. volume plotted in what is known as a P-V diagram (Figure 2).

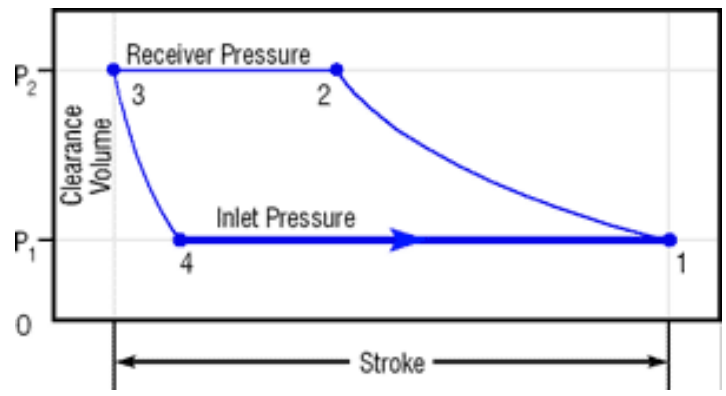

Figure 2. Theoretical PV diagram

At the conclusion of a prior cycle, the piston is fully retreated within the cylinder at V1, the volume of which is filled with process gas at suction conditions (pressure, P1 and temperature, $\mathrm{T} 1$ ), and the suction and discharge valves are all closed. This is represented by point 1 (zero) in the $\mathrm{P}-\mathrm{V}$ diagram. As the piston advances, the volume within the cylinder is reduced. This causes the pressure and temperature of the gas to rise until the pressure within the cylinder reaches the pressure of the discharge header. At this time, the discharge valves begin to open, noted on the diagram by point 2 .

With the discharge valves opening, pressure remains fixed at P2 for the remainder of the advancing stroke as volume continues to decrease for the discharge portion of the cycle. The piston comes to a momentary stop at V2 before reversing direction. Note that some minimal volume remains, known as the clearance volume. It is the space remaining within the cylinder when the piston is at the most advanced position in its travel. Some minimum clearance volume is necessary to prevent piston/head contact, and the manipulation of this volume is a major compressor performance parameter. The cycle is now at point 3.

Expansion occurs next as the small volume of gas in the clearance pocket is expanded to slightly below suction pressure, facilitated by the closing of the discharge valves and the retreat of the piston. This is point 4 .

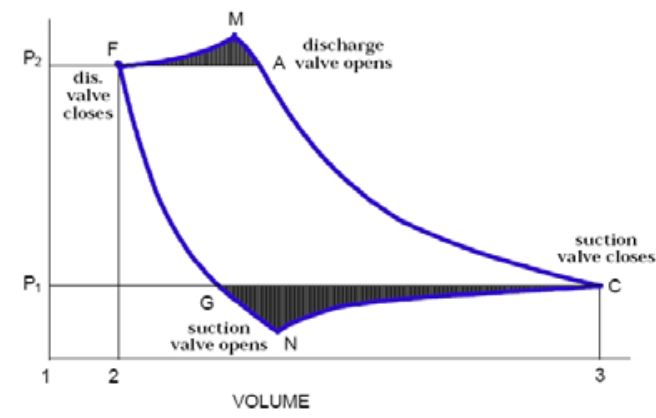

Figure 3. The actual PV diagram of reciprocating compressor
When $\mathrm{P} 1$ is reached, the intake valves open allowing fresh charge to enter the cylinder for the intake and last stage of the cycle. Once again, pressure is held constant as the volume is changed. This marks the return to point 1 .

Comprehending this cycle is key to diagnosing compressor problems, and to understanding compressor efficiency, power requirements, valve operation, etc. This knowledge can be gained by trending process information and monitoring the effect these items have on the cycle.

The most frequent reasons for unplanned outage of reciprocating compressors are faults in suction and discharge valves. As a result, these valve types are regarded as the main wearing parts, so particular importance is attached to early recognition and precise diagnosis of a defective valve. The situation inside the compression chambers can be continuously evaluated directly by permanent measurement of cylinder pressure. The measured time characteristic of this pressure is also presented in the form of a p$\mathrm{V}$ diagram, from which characteristic values are calculated and monitored.

The following example, from a refinery operating a $700 \mathrm{~kW}$ two-stage, double-acting hydrogen compressor, demonstrates the characteristic changes in signals associated with damage to a pressure valve. Fig. 1 shows the P-V diagrams of the crank-end in the first and second stages. In our example, the monitoring system signalled a violation of the vibration thresholds in the first-stage cylinder and disturbance of the $\mathrm{p}-\mathrm{V}$ characteristic values of the crank end compression. Fig. 2 demonstrates the vibration and pressure characteristics recorded at the time of the alarm for one crank revolution. There is increased cylinder vibration during almost the entire crank stroke, less vibration being evident only within the discharge region $\left(70^{\circ}\right.$ to $180^{\circ}$ crank angle) of the crank-end compression space. The changes are even more obvious on comparison with the first- and secondstage P-V diagrams (Fig. 4).

The first-stage P-V diagram is visibly distorted and no longer reaches the target intermediate pressure of 20.3 bar. The compression ratio in the second stage rises because of the decrease in ultimate pressure in the first stage.

The analysis shows that the compression curve is steeper, while the re-expansion curve is flatter, so in these regions, gas is overflowing from the discharge side into the cylinder space. This is normally prevented by proper sealing of the discharge valves. It was, therefore, diagnosed that the problem could be due to a damaged discharge valve. Indeed, this was the case. Other possible causes, such as leakage along the piston rings, for instance, could be ruled out, because in that case, direction of gas overflow alternates between the cylinder crank-end and head-end during one crank revolution. Compression and backexpansion would then both be steeper as a result. The conspicuously increased vibration (which has also produced an alarm signal) is caused by flow-induced noise and chattering of the faulty valve plate. 


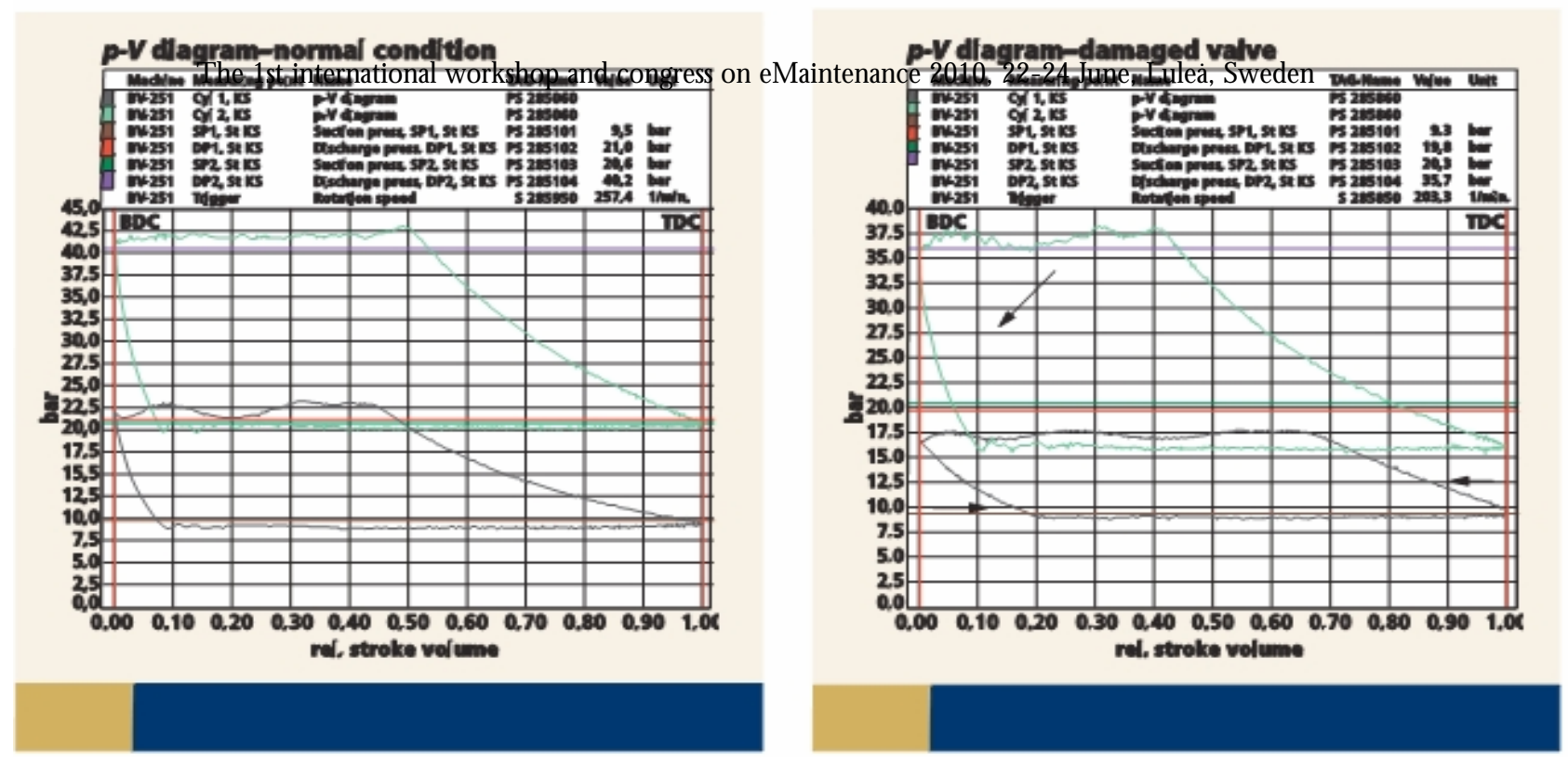

Fig -4 (left side)P-V diagram of first- and-second stage cylinder

With properly operating discharge valves

Reciprocating compressor dynamic analysis is based on the interpretation of deviation of its operating parameters from ideal conditions. Parameters to be analyzed include cylinder internal pressures, volumes, temperatures, phase, vibrations and rod drop. The analysis also includes calculated parameters such as power, efficiency, rod loads and losses.

Continuous online monitoring of reciprocating compressors through dynamic analysis allows malfunction diagnosis, improving the time and cost to repair and provides continuous protection from catastrophic events such as rod or cylinder rupture. The Pressure $x$ Volume $(\mathrm{PxV})$ diagram is the best way to represent the energy cycle in a reciprocating machine. Theoretical $\mathrm{P} \times \mathrm{V}$ diagrams superimposed on the actual diagrams supplies important compressor diagnostic information.

Pressure velocity (PV) analysis is a technique that has proven to be very effective in assessing the condition of reciprocating machine. Personal computer technology has significantly reduced the cost of this kind of measurement, and improvements in transducer technology have overcome the technical obstacles such that PV analysis is now available online. Dynamic pressure transducers are used to measure the pressure inside the cylinder over the course of the stroke. This allows the analyst to evaluate the condition of the rings, valves, and packing, while at the same time

calculating the dynamic rod load, which is the source of the forces and moments described in the discussion on vibration. This requires that a pressure transducer be installed in the cylinder, either on a temporary basis using a valved port or for an online measurement using a permanent transducer installation. While it is true that a direct measurement of the compressor pressure volume trace utilizing a dynamic pressure transducer gives the most accurate picture of cylinder condition, a performance calculation based on the pressures, temperatures, and flows already available in the process control system provides a valuable overview of the condition of the machine. Establishing a baseline of performance when it is known that there are no problems with the machine makes it possible to identify deviations from normal, alerting operations and maintenance to a developing problem, and perhaps giving operations a chance to

take action to mitigate the problem before it causes a machine failure.

(Right side)P-V diagram of first- and-second-stage crank-end cylinder with faulty first-stage crank-end discharge valve.

Other than the failure diagnosis of different components of the compressor, failure prognosis can be done by analyzing the past data.

\section{CONCLUSIONS}

By leveraging information, wireless and internet technologies users may log in from anywhere and with any kind of devices as soon as they set an internet connection and a browser. This allows them to take remote actions, such as set up configuration, diagnosis, performance monitoring and data collection and analysis. Consequently, the manpower on the customer site of many machine builders can be reduced and preventive maintenance can be improved through machine performance monitoring .E-diagnostics also offers the opportunity to connect field systems with expertise centers located at distant geographical sites, allowing the possibility of a remote maintenance decision making.

An e-maintenance platform significantly contribute to a lean process and help to synchronize maintenance with production, maximizing process through put and minimizing downtime cost. Data and information flow at all level can be improved. Emaintenance connects geographically dispersed subsystems and actors (e.g. suppliers with clients and machinery with engineers). The resultant platform allows a strong co-operation between different human actors, different enterprise areas (production, maintenance, purchasing) and different companies (suppliers, customers, machine manufacturers). The e-Diagnostics helps to increase the availability of production equipments, reduce the mean time to repair and provide significant reduction in field service resource and cost .Many plant operators have come to recognize the economic significance of e- monitoring, especially in regard to machines whose central importance could stop production of a whole plant on failure. Often, investment in such a system will pay for itself simply by preventing a production stoppage lasting just one day. The increasing popularity of online systems has been accelerated too, by the possibility of unmanned compressor operation through remote monitoring, for example, 
via the internet. Real time machine monitoring of equipment status besides programmable alerts enables the operator to respond to any situation swiftly and then to prepare any intervention.

\section{REFERENCES}

[1] Campbell, J. D and Jardine, A. K. S. (2001), Maintenance excellence: optimizing equipment lifecycle decisions. Marcel Dekker, New York,

[2] De Ron, A. J. and Rooda, J. E. (2005) Equipment effectiveness: OEE revisited. IEE Transactions on Semiconductor Manufacturing, 18, 1, 190-196.

[3] De Ron, A. J. and Rooda, J. E. (2006) OEE and equipment effectiveness: An evaluation. International Journal of Production Research, 44, 23, 4987-5003.

[4] ISO/IEC 15288, (2002), Systems Engineering: System Life Cycle Processes, International Organization for Standardization, Geneva Commission Electrotechnique Internationale, Geneva.

[5] Koc, M and Lee, J. (2001). A system framework for next-generation symposium on environmentally conscious design and inverse manufacturing", Tokyo, Japan.

[6] Lee, J; Ramji, A; Andrews, K. J. S; Daming, L and Dragan, B (2004), An integrated platform for diagnostics ,prognostics and maintenance optimization , E-proceedings of intelligent maintenance system , 1517 July 2004, Arles, France.

[7] Ljungberg, Ö. (1998) Measurement of overall equipment effectiveness as a basis for TPM activities. International Journal of Operations \& Production Management, 18, 5, pp.495-507

[8] Lyytinnen, K and Hirschheim, R (1987), Information system failures: a survey and classification of the empirical literature, Oxford surveys in information technology. Oxford University Press, Oxford, pp. 257309.
[9] Muller, A.; Marquez, A. C and Iung, B (2008). On the concept of eMaintenance: Review and current research, Reliability Engineering \& System Safety, 93, pp. 11651187

[10] Nakajima, S. (1988) Introduction to TPM: total productive maintenance, Cambridge, Mass., Productivity Press.

[11] Parida, A. and Kumar, U. (2004). Managing information is key to maintenance effectiveness, Published in the e-Proceedings of the Intelligent Maintenance System's (IMS), 2004, July 15-17, 2004, Arles, France.

[12] Parida, A.; Phanse, K. and Kumar, U. (2004). An integrated approach to design and development of emaintenance system. Parida, A.; Phanse, K. and Kumar, U. (2004). VETOMAC-3 and ACSIM-2004, NewDelhi, Dec 6-9, pp. 1141-1147

[13] Söderholm, P and Akersten, P. A, (2002), Aerospace Diagnostics and Prognostics in a TQM Perspective, Proceedings of the 15th International Congress of COMADEM 2002, 2-4 September, Birmingham, UK, p. 80-89

[14] Sheu, D. D. (2006) Overall input efficiency and total equipment efficiency. IEEE Transactions on Semiconductor Manufacturing, 19, 4, 496-501.

[15] Tsang A.H.C. (2002). Strategic dimensions of maintenance management, Journal of Quality in Maintenance Engineering, Vol. 8, No. 1, pp. 7-39.

[16] Wohllwend, H (2005), E-diagnostics guidebook. Rev 2.1, Technology Transfer \#01084153D-ENG, SEMATECH manufacturing initiative. 